NG81h 80-212s

Modeling for Determination of Temperatures of Electrical Cables Within Thermally Insulated Walls

\begin{tabular}{l}
\hline$Q C$ \\
100 \\
.456 \\
$80-2129$ \\
1980 \\
$c .2$
\end{tabular}



NBSIR 80-2129

.1

\section{MODELING FOR DETERMINATION OF TEMPERATURES OF ELECTRICAL CABLES WITHIN THERMALLY INSULATED WALLS}

David D. Evans

Center for Fire Research National Engineering Laboratory National Bureau of Standards U.S. Department of Commerce Washington, D.C. 20234

October 1980

Interim Report

Prepared for:

Department of Energy

Washington, D.C. 20545

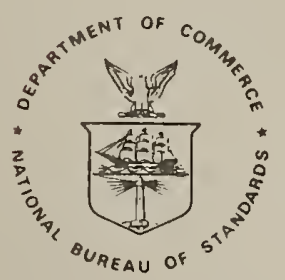

U.S. DEPARTMENT OF COMMERCE, Philip M. Klutznick, Secretary Luther H. Hodges, Jr., Deputy Secretary Jordan J. Baruch, Assistant Secretary for Productivity, Technology, and Innovation NATiONAL BUREAU OF STANDARDS, Ernest Ambler, Director 
$3:-1: 2:=10=12$

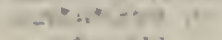

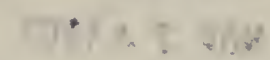




\section{PREFACE}

This report is one of a group documenting National Bureau of Standards research and analysis efforts in developing energy and cost data in support of the Department of Energy (DoE)/National Bureau of Standards (NBS) Building Energy Conservation Criteria Program. This work was supported by DoE/NBS Task Order A008-BCS under Interagency Agreement No. EA 77 A 016010 . 
PREFACE ...............................

LIST OF FIGURES ......................... v

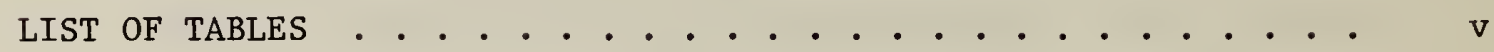

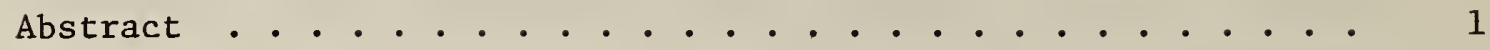

1. INTRODUCTION ............................ 1

2. EXPERIMENTAL DATA ....................... 3

3. MODELS ............................ 4

3.1350 Node Network - Wall Mode1 . . . . . . . 5

3.23 Node - Cylindrical Model ........... 8

3.3 13 Node Model - Heat Sink Effects of Wood Studs . . . 10

4. CONCLUSIONS ............................. 12

5. ACKNOWLEDGEMENTS ....................... 13

6. REFERENCES ........................... 13 
Figure 1. Typical wall section ............. . 14

Figure 2. Beausoliel's measurements for an AWG-12 2-G NM cable insulated with glass fiber . . . . . . . . .

Figure 3. Temperature distribution for an AWG-12 2-G NM cable with 20 amperes current load in a $12 \mathrm{~cm}$ thick insulation slab (one-half of slab thickness shown). .

Figure 4. Temperature distribution for an AWG-12 2-G NM cable with 20 amperes current load in an insulation slab with wood facing (one-half of slab thickness shown).

Figure 5. Temperature of AWG-12 electric cable in wall space with constant current flow of 20 amperes (heat flow perpendicular to the cable) . . . . . . . . 18

Figure 6. Thirteen node model of wall space . . . . . . . . 19

Figure 7. Predicted and measured temperature profiles - AWG-12 cable, 20 amperes ...............

Figure 8. Predicted and measured temperature profiles - AWG-12 cable, 15 amperes ...............

Figure 9. Predicted and measured temperature profiles - AWG-12 cable, 27 amperes . . . . . . . . . . .

Table 1. Material thermophysical properties used in the calculations 



\title{
MODELING FOR DETERMINATION OF TEMPERATURES OF ELECTRICAL CABLES WITHIN THERMALLY INSULATED WALLS
}

David D. Evans

\begin{abstract}
Models have been developed to predict the temperature rise caused by resistive heating of a current-carrying electric cable within an insulated wall cavity, with emphasis on simplified models to minimize computation time. Predictions are compared to measurements performed on an AWG-12 2-G NM cable installed in a laboratory wall space mock-up. Results of the two-dimensional model are within 15 percent of the measured temperatures. The heat sink effect of the wood studs within the wall on the temperature rise of the section of cable passing through them is demonstrated both with experiment and calculation.
\end{abstract}

Key words: Electric wiring; resistive heating; thermal insulation; thermal model; wiring system.

\section{INTRODUCTION}

Existing electric cables strung through the wall cavity and attic spaces in a building may be encapsulated by thermal insulation. Accompanying the present increased use of thermal insulation have been questions about the potential harmful effects of increased operating temperatures for thermally insulating the building electrical wiring systems.

Electric current limits for cables are established by considering the temperature limits for the electrical insulation material used to cover the conductors in the cable. In establishing the operating temperatures of current-carrying electric cables, the heat generated by the current flow in the conductors is considered to be dissipated through 
the cable jacket directly into air at a temperature of $30^{\circ} \mathrm{C}[1]^{1}$. The established principle for general wiring is that no conductor shall be used under such conditions that its temperature, even when carrying current, will exceed the specific maximum operating temperature for the type of electrical insulator involved.

Thermal insulation surrounding electric cables inhibits the dissipatjon of heat generated by the electric current in the conductors. For thermally insulated cables the heat that normally would be dissipated from a current-carrying cable surface to the surrounding air must conduct through the layer of the thermal insulation before dissipation to the air. This additional insulation causes an increase in the temperature of the cable above that for a cable exposed directly to air under an identical current load condition.

Mr. Robert Beausoliel in the Center for Building Technology at the National Bureau of Standards (NBS) has conducted experiments in which the surface temperatures of an AWG-12 2-G NM electric cable routed horizontally through stud spaces within a laboratory wall mock-up were measured in strategic places [2]. Measurements were made of the transient temperature rise for the cable in response to 15 amperes, rated 20 amperes, and overload 27 amperes steady current.

Experimental investigations of the operating temperatures of electric cables over a range of current loads, insulation types, and installation conditions can be time consuming and costly. However, mathematical models can be developed to predict the transient temperature rise of the cable in response to a steady current load or to directly calculate the steady operating temperatures. Mathematical models, once verified by comparison with existing test data such as those available from Beausoliel's tests, may be used to extend the data to other conditions of interest.

${ }^{1}$ Numbers in brackets refer to the references listed in section 6 . 
Mathematical models vary in complexity. Detailed models that are capable of accounting for all the physical phenomena involved in transient heating problems require large and efficient computer systems to execute. To achieve greatest accuracy, small space and time step intervals requiring large storage and execution times must be used to provide solutions of interest. Approximate models that account for the salient features of the configuration of the thermally insulated wire, but simplify the calculation effort by lumping the effects of various materials and geometries into a simple thermal network for analysis, are also available. The approximate models can provide solutions with sufficient accuracy for engineering or design purposes from computer codes that do not require burdensome storage or execution times.

This report discusses the features of several models of varying complexity, all directed towards predicting the temperatures of electric cables in an insulated wall space with geometry similar to the walls tested by Beausoliel. In previous work by Evans [3] steady operating temperatures for insulated wires were calculated based on a cylinder of insulation surrounding the cable. Calculations are presented in this report that demonstrate, for comparative purposes, the transient temperature rise of a cable surrounded by a cylinder of insulation as well as the same cable buried within a slab of insulation. Either calculation may be used to model electric cables within wall spaces. A simple thermal network is constructed as an approximate method of predicting the cable temperature rise within the wall cavity, including the effects of wood studs and the cable termination.

\section{EXPERIMENTAL DATA}

Beausoliel [2] constructed three wall sections of the type shown in figure 1. Each wall section was insulated with one of three types of thermal insulation-- blown glass fiber, blown cellulose, and ureaformaldehyde foam. Using thermocouples attached to the cable: acket, temperatures were measured at the locations shown in figure $1 \mathrm{cn}$ the 
single cable in the upper half of the wall section, and a multi-cable configuration (not shown) in the lower half of the wall section. Three steady current loads were applied--15 amperes, rated 20 amperes, and overload 27 amperes.

To limit the scope of the modeling work reported here, only the data for the single cable in the glass fiber insulated wall tests of Beausoliel [2] were studied. Figure 2 presents the measured temperature of the cable jacket under the three current loads for the single cable at locations $1,4,6$ and 8 as indicated in figure 1 . Thermocouple 8 in the center of the wall cavity showed the greatest temperature rise at a11 current loads. The temperature at location 4, in the adjacent end stud space, was slightly lower than at location 8 . The temperature at location 6 , where the cable passed through a hole in the wood stud was lower than in either adjacent stud space. This indicates that some heat conducted along the cable towards the wood stud from both adjoining insulated spaces. This stud, as well as the others, acted as heat sinks. The temperature at the exposed end stud, location 1, was the lowest of those measured along the cable.

\section{MODELS}

In the wall section mock-up, typical of home construction, shown in figure 1, an electric cable is embedded in an insulation layer approximately $9 \mathrm{~cm}$ thick which is sandwiched between the wall facing materials which also provide additional insulation. The total wall section including facing materials varies in thickness from 12 to $14 \mathrm{~cm}$. To dissipate the resistive heat generated by current flow in the cable conductors, the cable must operate sufficiently above ambient temperature to conduct the heat generated through the thermally insulated wall space. In this section of the report various methods used for determining the temperature rise of the current-carrying electric cable will be discussed. 


\subsection{Node Network - Wall Model}

The simplest and most direct method of obtaining transient temperature predictions for the cable within an insulated wall space is to code an explicit three-dimensional network that accounts for the geometry and the different materials involved. The disadvantage with this approach is that a prohibitive amount of computation time is usually needed to obtain a full transient solution.

If attention is restricted to sections of the wall in which heat flow is predominately perpendicular to the axis of the cable, a twodimensional model for heat conduction in the wall cross section may be sufficient to provide accurate predictions of the cable operating temperatures. In the test walls constructed by Beausoliel, position 8, which is far away from the heat sink effect of the studs, as indicated in figure 1 , best satisfies this condition.

For comparative purposes, the temperature distributions throughout the cross sections of two different insulated wall space configurations containing a current-carrying electric cable were calculated. If a cable is located in the center of the wall cross section, the entire temperature distribution throughout the cross section may be determined by only modeling one quadrant and making use of the symmetry. For a cable located in the center of a $12 \mathrm{~cm} \times 98 \mathrm{~cm}$ wall cross section, one quadrant ( $6 \mathrm{~cm} \times 49 \mathrm{~cm}$ ) may be modeled using a 350 node grid with a uniform square array with $1 \mathrm{~cm}$ spacing. With this model, the node located in one corner of the quadrant represents the cable. The boundaries of the rectangular-shaped quadrant intersecting this corner must be lines of symmetry. The remaining two sides represent ambient conditions and were modeled as the fixed constant temperature boundaries.

Using the 350 node system as described, transient temperature conditions were calculated using an explicit forward differencing calculation initiated with all nodes at the ambient temperature of $25^{\circ} \mathrm{C}$. 
This calculation method is described by Rohsenow and Hartnett [4]. The general recursive formula uses information available at time to calculate conditions at $t+\Delta t$ :

$T_{i}(t+\Delta t)=\frac{\Delta t}{c v_{i}}\left[\sum_{j} k_{i j} T_{j}(t)+\left(\frac{c v_{i}}{\Delta t}-\sum_{j} k_{i j}\right) \cdot T_{i}(t)+\dot{Q}_{i}\right]$

where $\mathrm{T}_{i} \quad$ is the temperature at the $i$-th node.

$t \quad$ is time.

$\Delta t \quad$ is time step.

$\mathrm{cv}_{i}$ is the thermal mass associated with the $i-t h$ node.

$k_{i j} \quad i s$ the thermal conductance between the $i-t h$ and adjoining
$j-t h$ node.

$\dot{Q}_{i} \quad$ is the heat generation rate at the $i-t h$ node.

Direct application of equation 1 to the one centimeter spacing grid around the node representing the cable would not produce accurate predictions of the cable jacket temperature. Special calculations were needed in this area of the grid because physically the location of the cable jacket surface (radius 0.51 ) within the wall cross section being modeled did not correspond to any grid points. Without changing the grid size, the accuracy of the calculation may be improved by considering thermal conduction between the corner node representing the cable jacket and the three adjacent nodes as special cases with modified thermal conductances differing from the values that would be calculated based on a straightforward analysis of the square grid. Effectively this extends the representation of the cable jacket surface to the three nodes adjacent to the corner. A straightforward calculation based on the uniform grid proceeds from these three nodes.

The thermal conductances from the corner node representing the cable jacket to the adjoining three nodes were calculated based on radial conduction of heat. Considering the symmetry boundaries at this 
corner, the conductances to the two nodes on the boundaries are given by:

$$
\mathrm{K}=\pi \mathrm{k} /[8 \ln (1 / 0.51)]
$$

where $k$ is the thermal conductivity of the glass fiber insulation material. The conductance to the third node, diagonally across the $1 \mathrm{~cm}$ square grid space, is given by:

$$
\mathrm{K}=\pi \mathrm{k} /[4 \ln (\sqrt{2} / 0.51)]
$$

No direct conduction between the three nodes adjacent to the corner node was assumed.

Discussions of the use of symmetry in thermal conduction problems and methods to determine the thermal conductance between cylindrical shells can be found in the textbook by Kreith [5].

For all calculations, the heat generated at the corner node representing the cable was considered to be a function of both current and the temperature of the node. For the AWG-12 cable, the resistive heat generation per centimeter of cable length (Q) in units of $\mathrm{W} / \mathrm{cm}$ was given by:

$$
\dot{Q}=2 \cdot I^{2} \cdot 4.8\left(1+0.00427 \mathrm{~T}_{\mathrm{W}}\right) \cdot 10^{-5}
$$

where $I$ is the current in amperes and $T_{W}$ is the cable jacket temperature in degrees Celsius [3]. In the model only one quarter of the heat generated is conducted into each quadrant.

Other thermal and physical properties of the material used in the calculations are given in table 1.

Part of the total network and steady temperature distributions for the two cases calculated are shown in figures 3 and 4 . In figures 3 and 4, the cable is shown in the lower left-hand corner of the grid. The 
temperatures shown in figure 3 are the steady conditions for an AWG-12 2-G NM cable carrying 20 amperes within a $12 \mathrm{~cm}$ thick slab of glass fiber insulation material. The solution in figure 4 differs from figure 3 only by the substitution of a $1 \mathrm{~cm}$ thick wood facing material at the ambient temperature edge in place of an equivalent thickness of insulation. Taking note of symmetry, figure 4 is the typical representation of the two-dimensional conduction in a wall space with a $10 \mathrm{~cm}$ thick layer of insulation faced on each side by a $1 \mathrm{~cm}$ thick layer of wood material. As can be seen by comparison, the substitution of wood facing material for $1 \mathrm{~cm}$ of insulation resulted in a $2.0^{\circ} \mathrm{C}$ decrease in steady operating temperature of the cable jacket.

The steady operating temperatures shown in figures 3 and 4 were the final steady-state result of a calculation of the transient temperature conditions within the wall space.

\subsection{Node - Cylindrical Model}

The geometry of the wall space is complicated and the effective overall thermal conductance for heat transfer from the embedded cable to the exterior is difficult to calculate. If attention remains fixed on sections of wall space where heat flow is predominately perpendicular to the axis of the cable, as discussed in the previous section, upper bound estimates of the thermal conductance of the wall space may be calculated based on a simple cylindrical geometry. The steady cable temperatures calculated on the basis of insulation by a $12 \mathrm{~cm}$ diameter cylinder of insulation will be equal to or lower than those calculated based on the more complicated $12 \mathrm{~cm}$ thick slab of insulation simulating a wall geometry discussed in the previous section.

To estimate the accuracy of the cylindrical shell approximation to the wall geometry a comparative case to the $12 \mathrm{~cm}$ thick slab solution (see figure 3) was calculated. 
Using the same thermal properties, the transient temperature rise for an AWG-12 2-G NM cable was calculated for a $12 \mathrm{~cm}$ diameter cylinder of glass fiber insulation surrounding the cable. The symmetry of the cylindrical geometry reduces the two-dimensional calculation for the wall geometry to a one-dimensional calculation. In the cylindrical approximation only three nodes are used. One node is used to represent the cable, a second to represent the thermal insulation at the radius dividing the insulation into two equal masses, and the third to represent ambient conditions at the outer surface of the insulation cylinder. The explicit calculation scheme given by equation 1 applies to this calculation where values of thermal conductance and thermal mass associated with each node are based on calculations assuming cylindrical shells and the properties in table 1.

A comparison of the results between the temperature rise predicted on the basis of the 350 node model for the $12 \mathrm{~cm}$ thick slab and that for the 3 node $12 \mathrm{~cm}$ diameter cylindrical model is shown in figure 5 for a 20 ampere current load. The initial rates of temperature rise for both models are nearly equal as would be expected, because the boundary should have little influence at early times. At steady state, however, the cable jacket temperature calculated by the approximate cylindrical mode $1\left(68.2^{\circ} \mathrm{C}\right)$ is 8 percent below the value calculated with the 350 node network and wall geometry $\left(74.0^{\circ} \mathrm{C}\right)$. To produce equal steady temperatures the diameter of the cylinder would have to be increased 32 percent to $15.8 \mathrm{~cm}$.

The steady-state temperature of an insulated cable is underestimated by replacing the slab of insulation that simulates a wall space by a cylinder of insulation with diameter equal to the thickness of the slab. However, the approximations are useful, primarily because the simplicity greatly reduces the burden of the calculations. Execution times for the 350 node network are one thousand times that for the 3 node network. 
The great reduction in calculation time enables more complicated threedimensional effects such as conduction along the wire to be modeled using cylindrical approximations without producing large execution times for the computer code.

\subsection{Node Model - Heat Sink Effects of Wood Studs}

Using the simplification of cylindrical shells to reduce the burden of the calculation, a 13 node network was constructed that in the simplest way accounted for the effects of conduction both parallel and perpendicular to the cable direction. The cylindrical symmetry reduced the three-dimensional problem to a two-dimensional calculation. The thirteen node network was constructed to represent the one and one-half stud spaces instrumented in Beausoliel's tests [2]. This network is shown in figure 6, superimposed on a schematic of the wall space. Basically, the three node method of representing conduction through cylindrical shells perpendicular to the wire axis was used to represent insulation, wood stud, and cable material. Heat flow paths were also provided between these nodes to allow conduction parallel to the axis of the cable.

Equation 1 was used with a fixed boundary condition of ambient temperature at the outer boundary of the cylindrical shells and initial ambient temperature everywhere. Thermal conductance values perpendicular to the cable direction were calculated using

$$
\mathrm{K}=\frac{2 \pi k}{\ln \mathrm{r}_{\mathrm{o}} / \mathrm{r}_{\mathrm{I}}}
$$

and parallel to the cable direction using

$$
\mathrm{K}=\frac{\mathrm{kA}}{\mathrm{L}}
$$

where $r_{0}$ is the radial distance measured from the center of the cable to a node. 
$r_{I}$ is the radial distance measured from the center of the cable to the adjacent node $\left(r_{0} \geq r_{I}\right)$.

$A$ is the cross-sectional area of the cylindrical she11 $\pi\left(r_{0}^{2}-r_{I}^{2}\right)$.

$\mathrm{L}$ is the distance between nodes paralle1 to the cable direction.

$k$ the thermal conductivity of the material.

As with previous calculations the outer diameter of the cylindrical shell was set equal to $12 \mathrm{~cm}$ which was close to the thickness of Beausoliel's model test walls. Contact between various materials was considered intimate; contact resistance was assumed to be equal to zero. Thermal properties for the electric cable, thermal insulation, and wood stud materials used in the calculations are given in table 1 . The wood facing material was not modeled.

An explicit scheme, following equation 1, and using the 13 node model of the wall space was coded and executed. The results can be compared directly to measurements made by Beausoliel at the strategic thermocouple locations $1,4,6$, and 8 as illustrated in figure 1. Figure 7 shows both predictions and experimental data at the strategic points for $1 / 4,1 / 2,1$ and 4 hours after a steady current of 20 amperes was initiated in the AWG-12 cable.

As would be expected, considering the number of approximations used, the calculated temperatures do not agree exactly with measurements, but important characteristics are demonstrated. As discussed in section 3.2 the cylindrical model underestimates the steady temperature of the cable in the wall space geometry, so that the predicted temperatures after 4 hours current flow can be expected to be slightly lower than the measured values. It is interesting to note that the steady ( 4 hour) temperature predicted at position 8 is more than $5^{\circ} \mathrm{C}$ below the steady temperature predictions from the cylindrical geometry solution discussed in section 3.2 in which no heat flow was allowed parallel to the cable. This decrease is predominately due to heat flow along the cable towards 
the stud. Heat loss from the end stud at location 1 is overestimated by the calculations, giving lower calculated temperatures. As indicated, the agreement between the calculated and measured results is fair, but it is obvious that the effective thermal mass of the wood studs and cable are not modeled exactly. Although not performed, adjustments of thermal properties for each of the materials can produce better agreement between predictions and experiments.

For completeness, experimental results and calculated cable temperatures are compared for the cases of 15 amperes and overload 27 amperes current load on the AWG-12 cable in figures 8 and 9. Changes in the relative relationship between prediction and experimental data in the 27 amperes load case (figure 9), when compared to the 20 amperes load (figure 7), have been judged to reflect the influence of an increase in thermal conductance with increasing temperature for the insulation material. Temperature dependent thermal properties for the thermal insulation materials were not included in the model.

\section{CONCLUSIONS}

The predictions of the transient temperature rise of an electric cable buried in an insulated wall space show the heat sink effects of the wall studs through which the cable is routed. For the AWG-12 2-G NM cable, carrying 20 amperes current load, calculations show that conduction of heat along the wire to wood studs lowers the steady operating temperature at least $5^{\circ} \mathrm{C}$, compared to the operating temperature when no heat is dissipated parallel to the cable direction.

The present model can produce calculated results that are in fair quantitative agreement with laboratory measurements by choosing representative values for the thermal and physical properties of materials. Experimental data on the thermal properties of the insulation materials used in the experimental work for a range of temperatures are needed before further refinements in the model can be justified. 
For heat conduction perpendicular to the cable direction, a simple cylindrical shell approximation for the geometry of the wall space has been shown to be a useful approximation to determine thermal response.

\section{ACKNOWLEDGEMENTS}

The author is grateful for the assistance of Mr. Daniel Madrzykowski in coding the programs for the models and helping to prepare the graphics for this report.

\section{REFERENCES}

[1] Allowable Ampacities of Insulated Conductors Rated 0-2000 Volts, $60^{\circ} \mathrm{C}$ to $90^{\circ} \mathrm{C}$, Table 310-16, p. 132, National Electric Code, 1978, National Fire Protection Assn., Boston, MA.

[2] Beausoliel, R. W., Temperatures produced by self-heating of wiring when surrounded by thermal insulation within residential building walls, Nat. Bur. Stand. (U.S.), NBSIR in process.

[3] Evans, D. D., Calculated operating temperatures of thermally insulated electric cables, Nat. Bur. Stand. (U.S.), Tech. Note 1133 (1980).

[4] Rohsenow, W. M. and Hartnett, J. P., Handbook of Heat Transfer, p. 4-47 (McGraw-Hill Book Co., New York, NY, 1973).

[5] Kreith, F., Principles of Heat Transfer (International Textbook Co., Scranton, PA, 1965). 


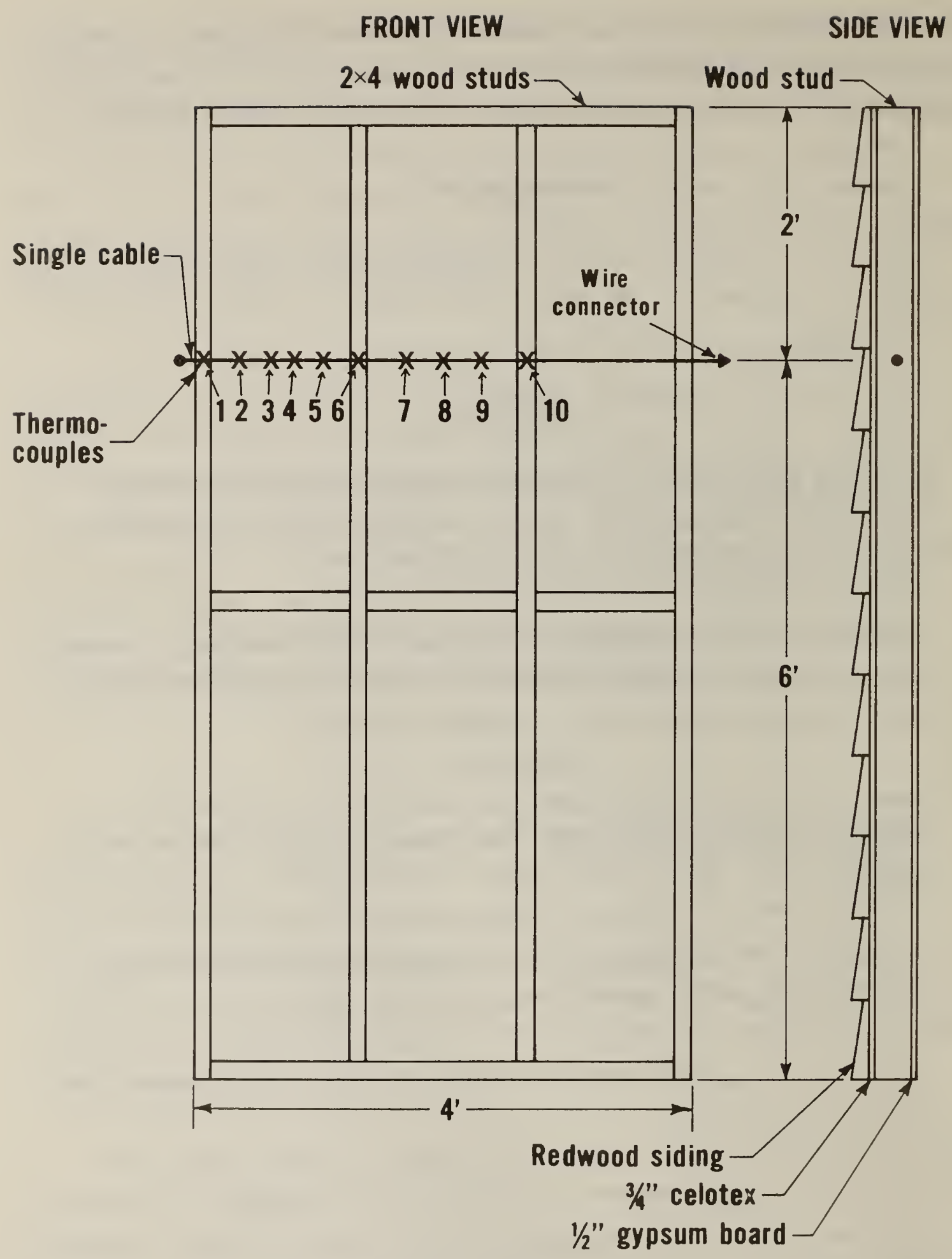

Figure 1. Typical wall section 


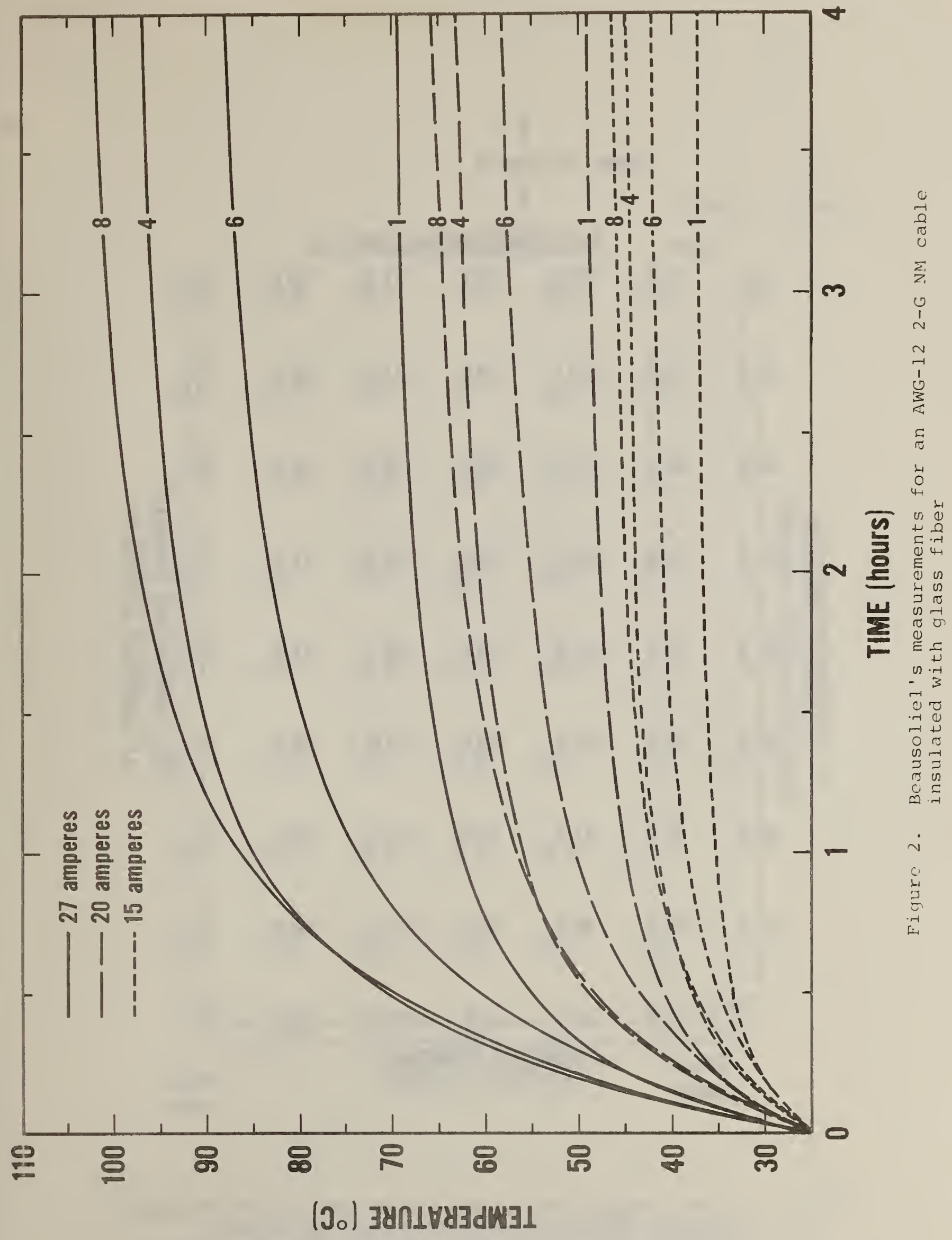




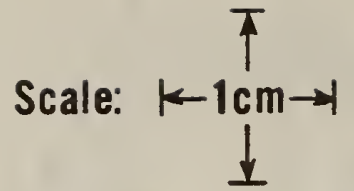

GLASS FIBER INSULATION

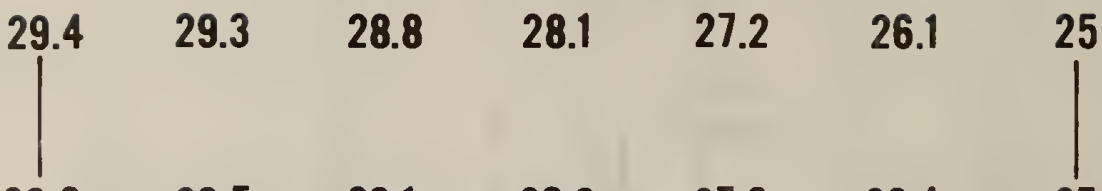

$\begin{array}{lllllll}30.8 & 30.5 & 30.1 & 29.0 & 27.8 & 26.4 & 25\end{array}$

$\begin{array}{lllllll}35.0 & 34.5 & 33.4 & 31.6 & 29.6 & 27.3 & 25\end{array}$

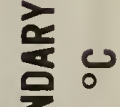

些

$\begin{array}{llllll}38.2 & 37.5 & 35.8 & 33.4 & 30.7 & 27.9\end{array}$

1

42.8<smiles>CCC</smiles>

50.0

47.1

42.6

37.8

33.4

29.1

25

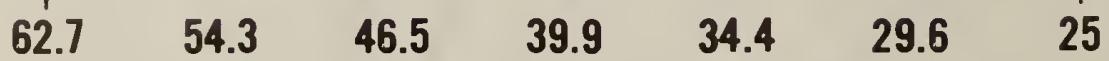

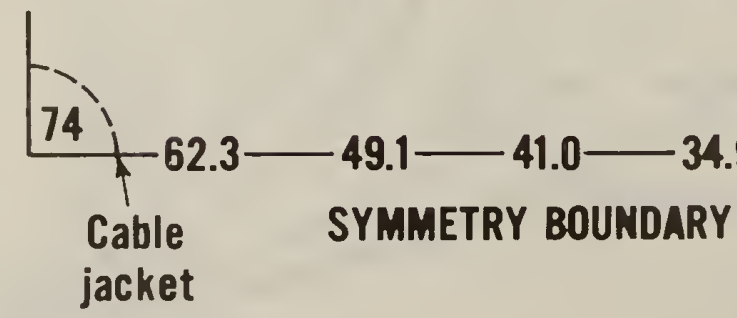

Figure 3. Temperature distribution for an AWG-12 2-G NM cable with 20 amperes current load in a $12 \mathrm{~cm}$ thick

insulation slab (one-half of slab thickness shown) 
GLASS FIBER INSULATION

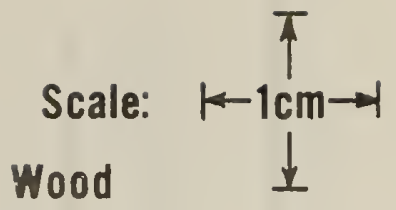

$\begin{array}{llllll}28.5 & 28.4 & 28.0 & 27.3 & 26.4 & 25.4\end{array}$

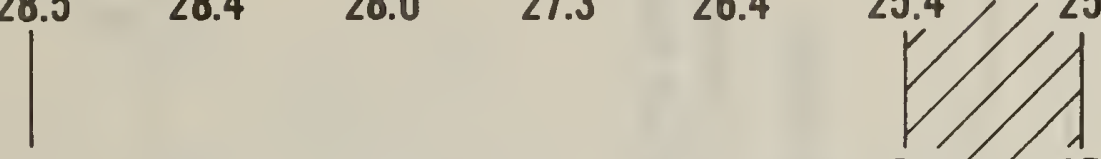

$\begin{array}{llllll}29.8 & 29.6 & 29.0 & 28.1 & 26.9 & 25.6\end{array}$

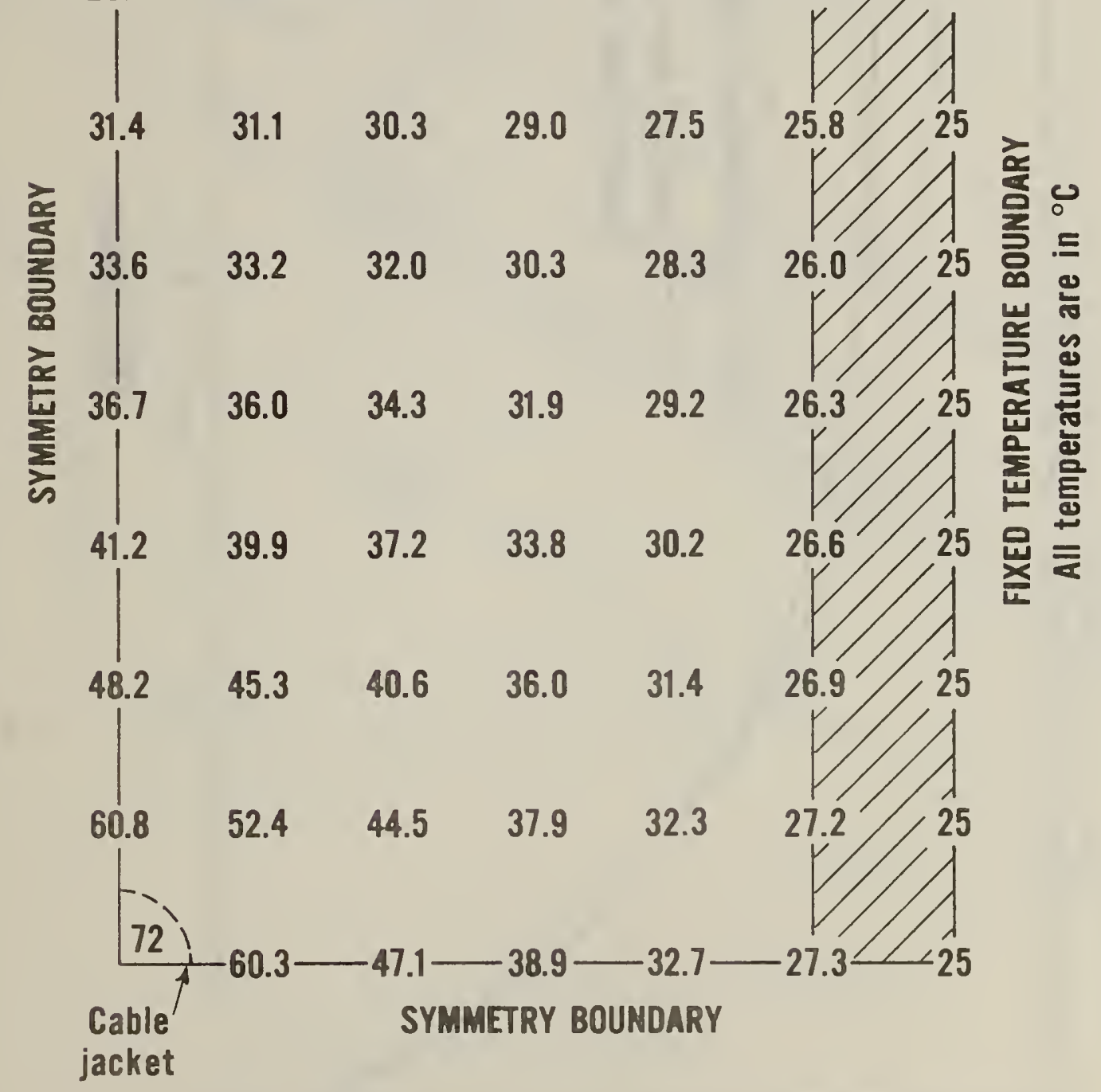

Figure 4. Temperature distribution for an AWG-12 2-G NM cable with 20 amperes current load in an insulation slab with wood facing (one-half of slab thickness showr) 


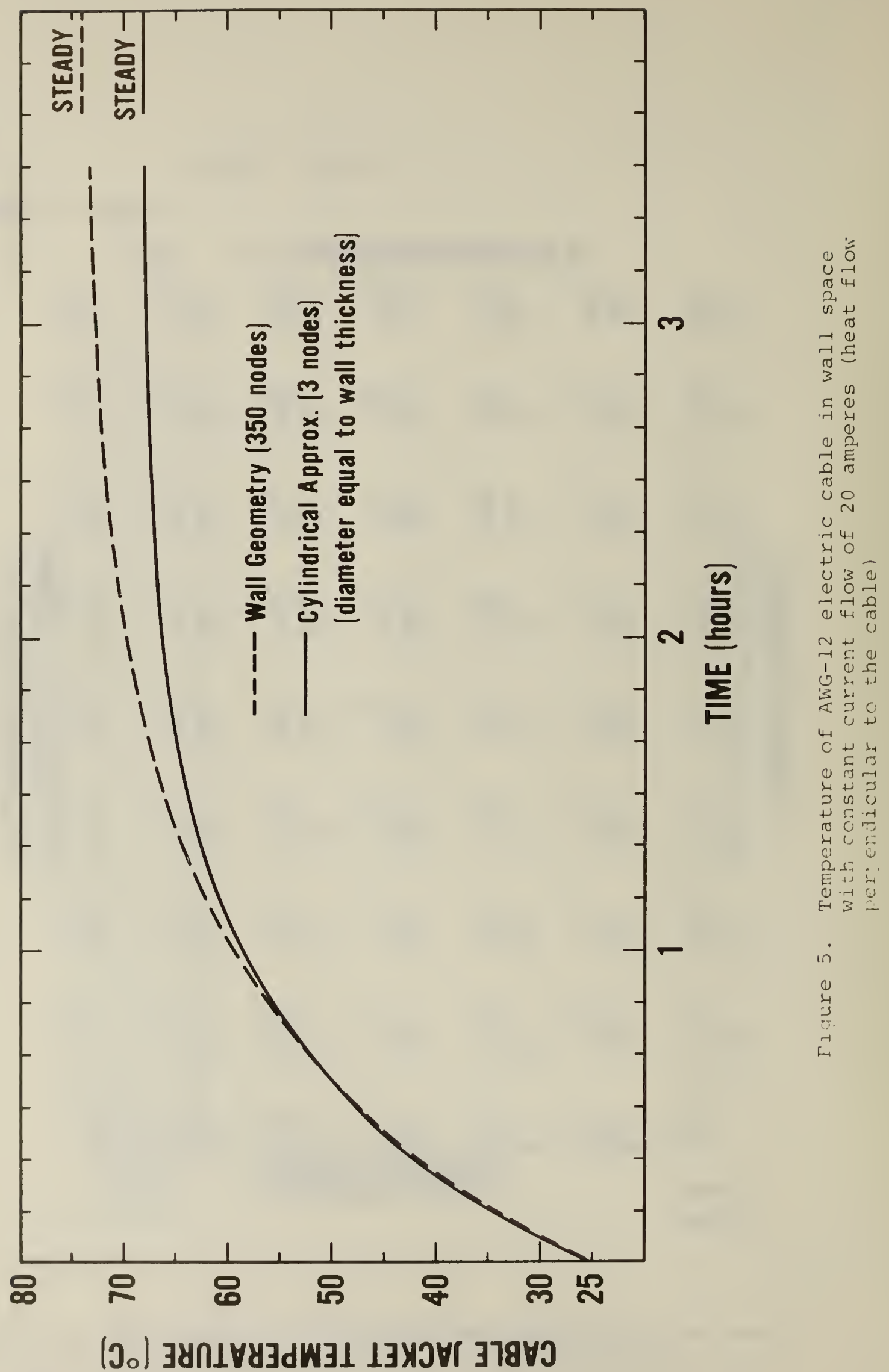




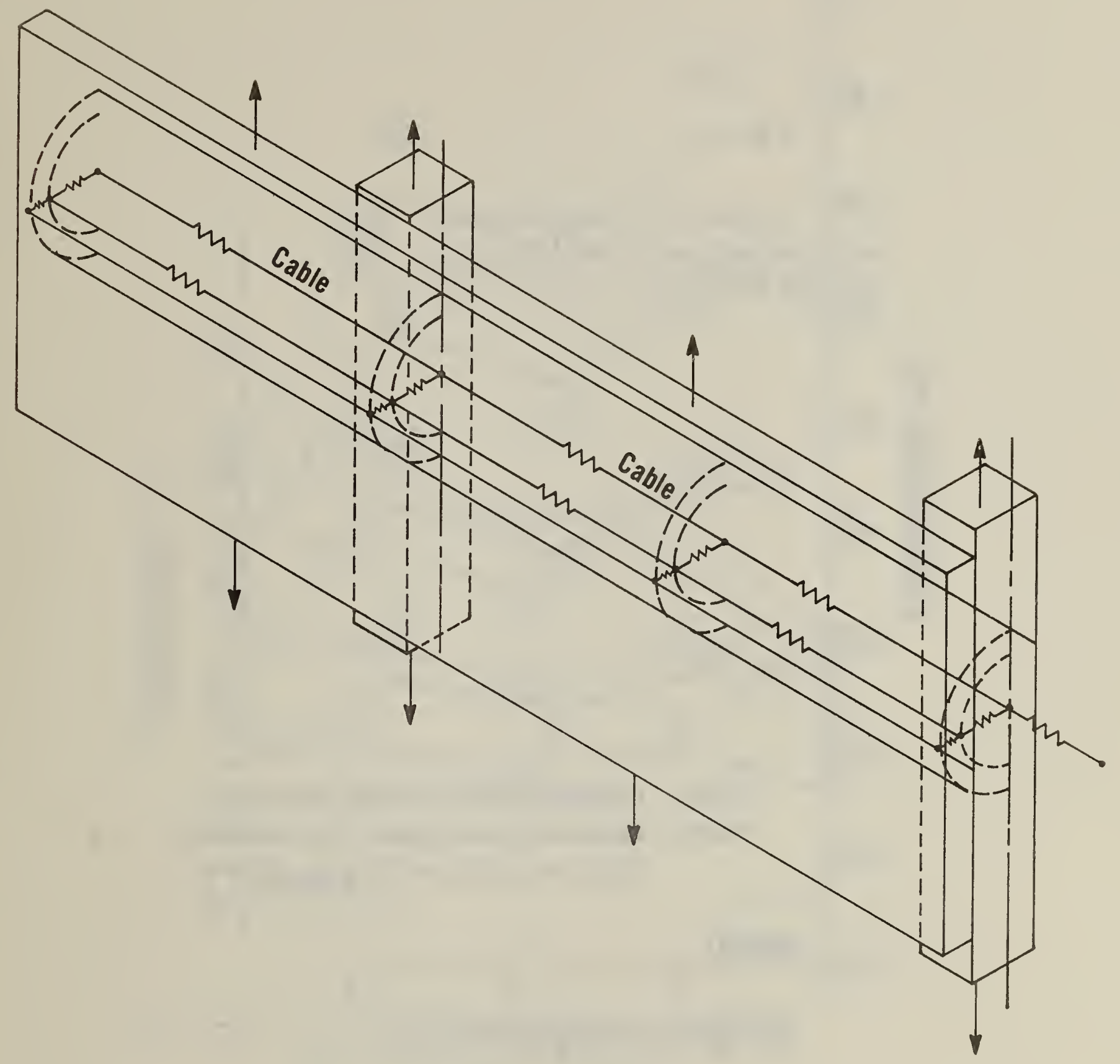

Figure 6. Thirteen node model of wall space 


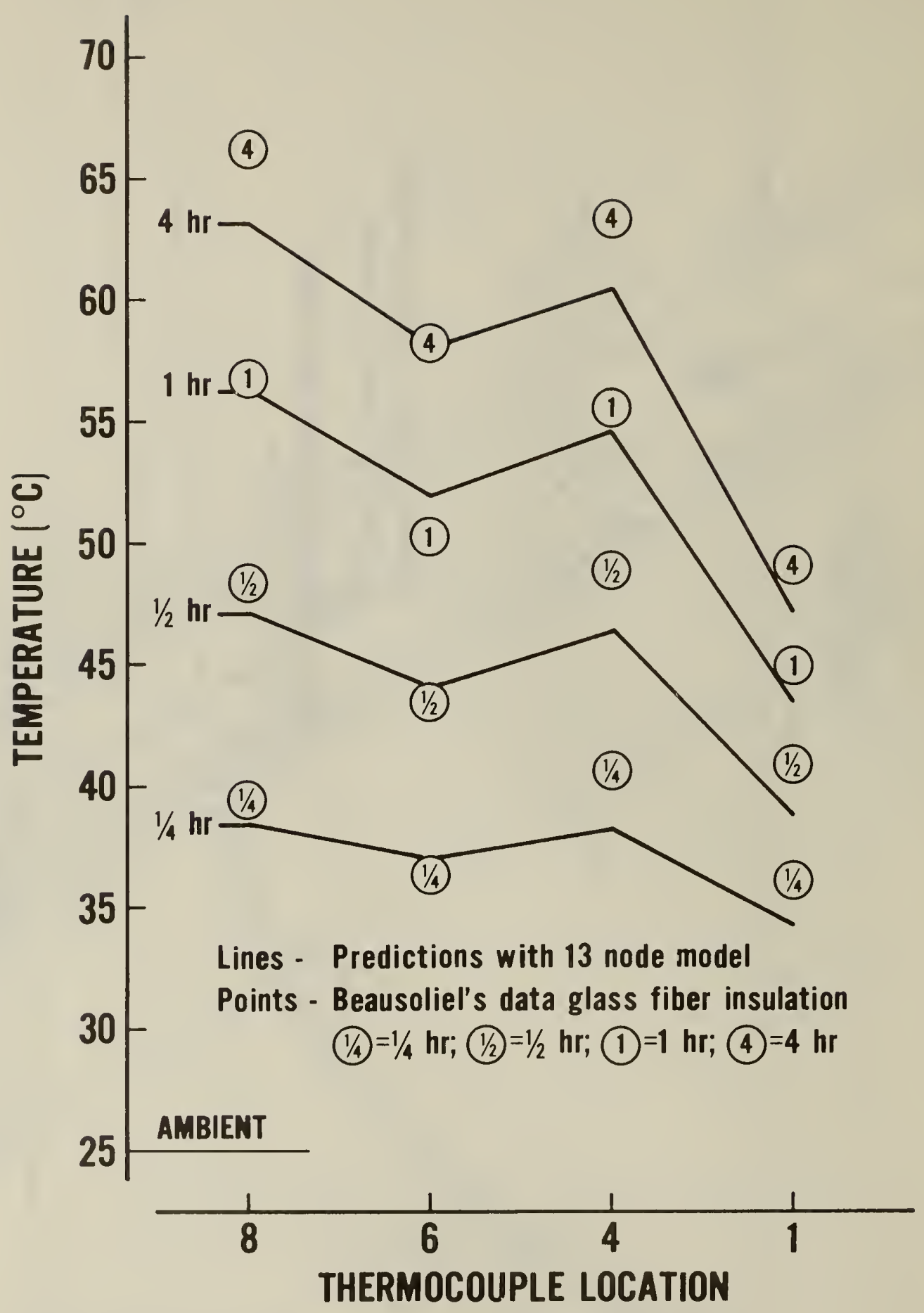

Figure 7. Predicted and measured temperature profiles AWG-12 cable, 20 amperes 


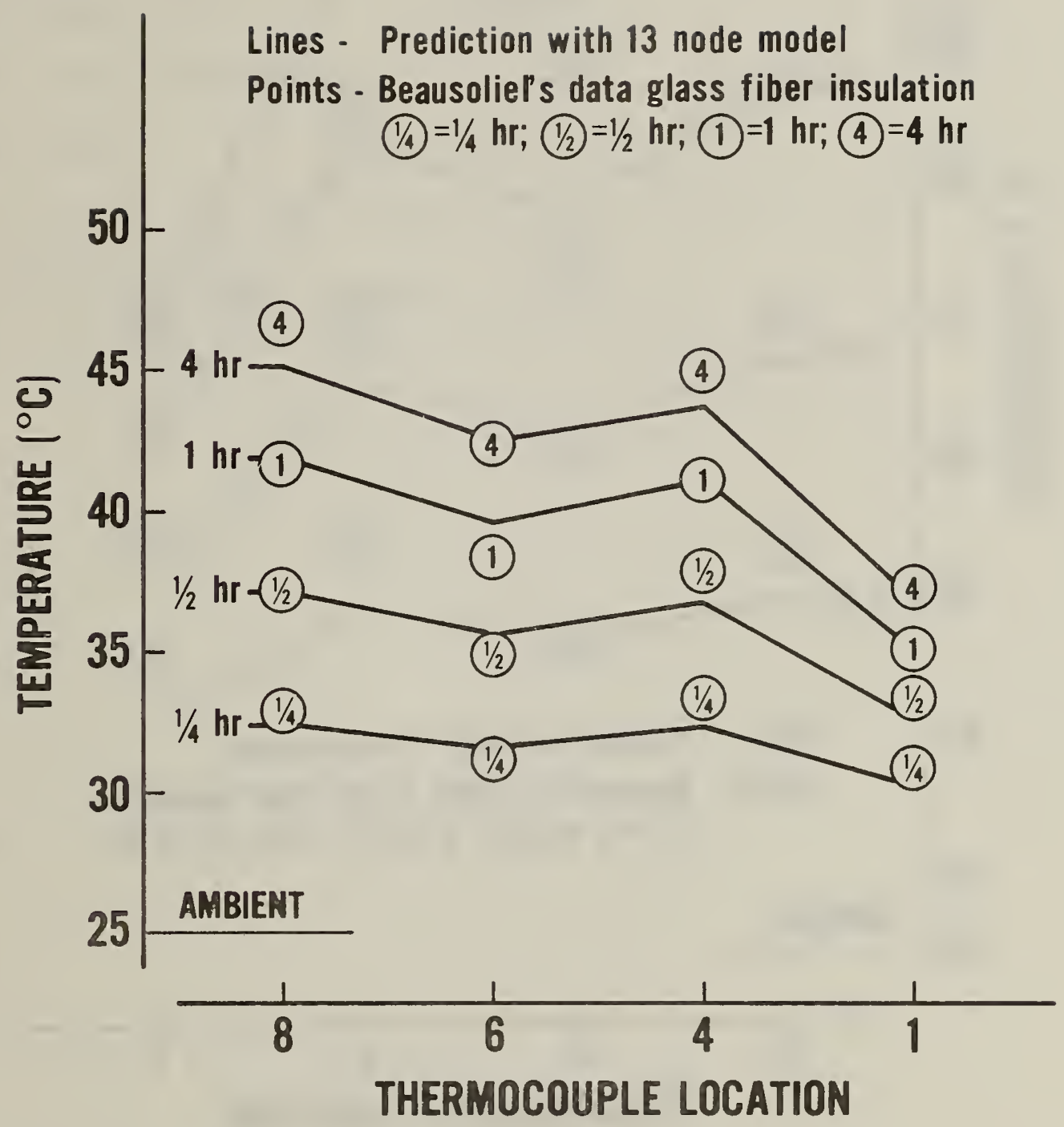

Figure 8. Predicted and measured temperature profiles AWG-12 cable, 15 amperes 


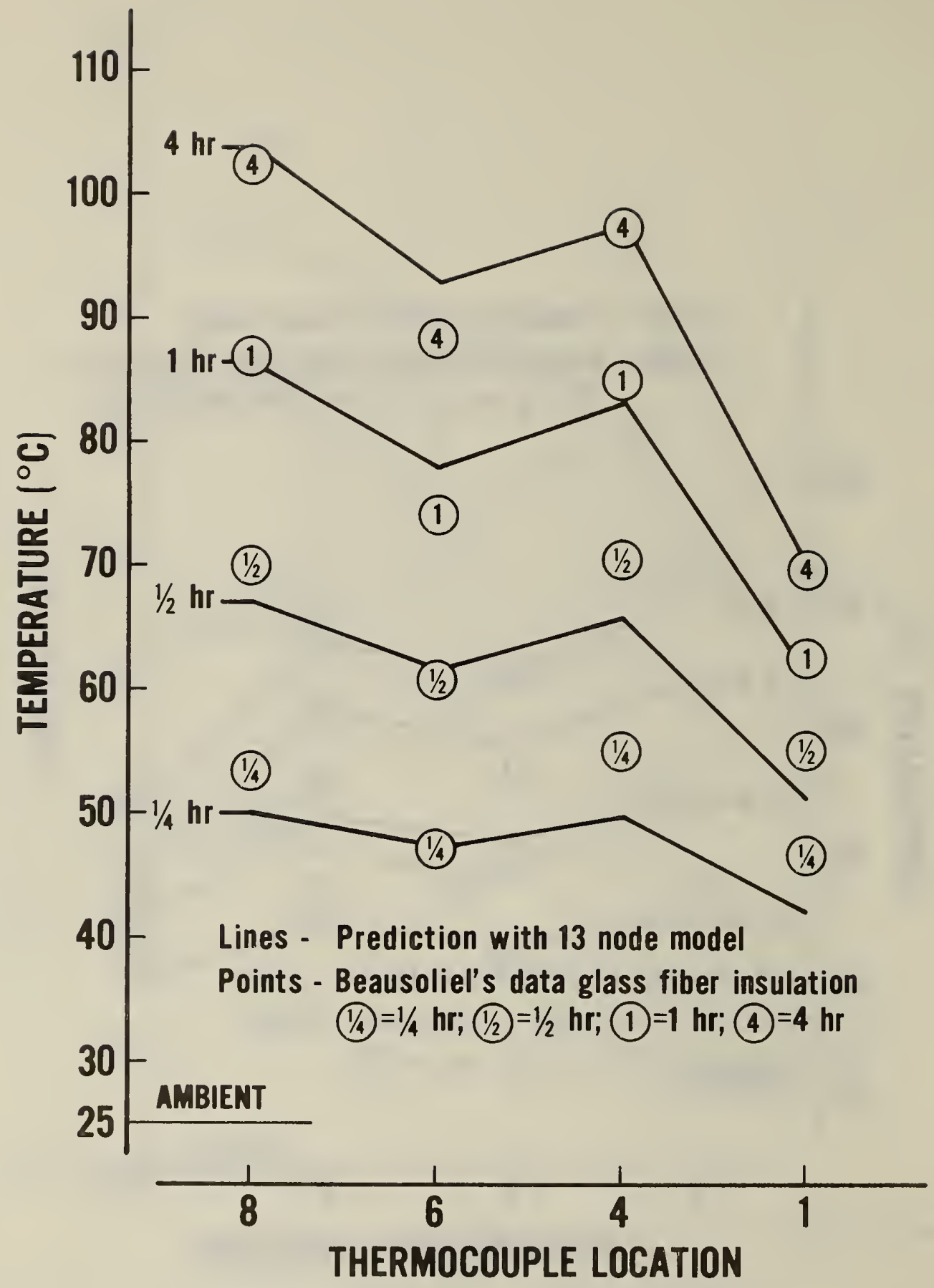

Figure 9. Tredicl ad and measured temperatuse plil l.e iWfi-l 2 :able, 27 amperes 
Table 1. Material thermophysical properties used in the calculations

\begin{tabular}{|l|c|c|}
\hline Material & $\begin{array}{c}\text { Thermal Conductivity } \\
\mathrm{W} / \mathrm{cm}^{\circ} \mathrm{C}\end{array}$ & $\begin{array}{c}\text { Volometric Heat Capacity } \\
\text { (density } \mathrm{x} \text { heat capacity) } \\
\mathrm{J} / \mathrm{cm}^{3}{ }^{\circ} \mathrm{C}\end{array}$ \\
\hline \#12 electric cable & $3.85 *$ & $2.86^{+}$ \\
Glass fiber insulation & $4.5 \times 10^{-4}$ & 0.021 \\
Wood facing & $1.0 \times 10^{-3}$ & 0.94 \\
\hline$*$ Copper wire only. & & \\
\hline
\end{tabular}


NBS-114A :REV : $9-76$;

\begin{tabular}{|c|c|c|c|}
\hline $\begin{array}{l}\text { U.S. DEPT. OF COMM. } \\
\text { BIBLIOGRAPHIC DATA } \\
\text { SHEET }\end{array}$ & $\begin{array}{l}\text { 1. PUBLICATION OR REPORT NO. } \\
\text { NBSIR } 80-2129\end{array}$ & 2.Gov't. Accession No. & 3. Recipient's Accession No. \\
\hline \multirow{2}{*}{\multicolumn{3}{|c|}{$\begin{array}{l}\text { 4. TITLE AND SUBTITLE } \\
\text { MODELINC. FOR DETERMINATION OF TEMPERATURES OF ELECTRICAL } \\
\text { CABI.ES WITHIN THERMALLY INSULATED WALLS }\end{array}$}} & $\begin{array}{l}\text { 5. Publication Date } \\
\text { October } 1980\end{array}$ \\
\hline & & & 6. Performing Organization Code \\
\hline \multicolumn{3}{|l|}{$\begin{array}{l}\text { 7. AUTHOR(S) } \\
\text { David D. Evans }\end{array}$} & 8. Performing Organ. Report No. \\
\hline \multirow{2}{*}{\multicolumn{3}{|c|}{ 9. PERFORMING ORGANIZATION NAME AND ADDRESS }} & $\begin{array}{l}\text { 10. Project/Task/Work Únit No. } \\
7425106\end{array}$ \\
\hline & & & 11. Contract/Grant No. \\
\hline \multirow{2}{*}{\multicolumn{3}{|c|}{$\begin{array}{l}\text { 12. SPONSORING ORGANIZATION NAME AND COMPLETE ADDRESS (Street, City, State, } z I P \text { ) } \\
\text { Department of Energy } \\
\text { Washington, D.C. } 20545\end{array}$}} & $\begin{array}{l}\text { 13. Type of Report \& Period Covered } \\
\text { Interim }\end{array}$ \\
\hline & & & 14. Sponsoring Agency Code \\
\hline
\end{tabular}

15. SUPPLEMENTARY NOTES

Document describes a computer program; SF-185, FIPS Software Summary, is attached.

16. ABSTRACT (A 200-word or less factual summary of most significant informatson. If document includes a significant bibliography or literature survey, mention it here.)

Models have been developed to predict the temperature rise caused by resistive heating of a current-carrying electric cable within an insulated wall cavity, with emphasis on simplified models to minimize computation time. Predictions are compared to measurements performed on an AWG-12 2-G NM cable installed in a laboratory wall space mock-up. Results of the two-dimensional model are within 15 percent of the measured temperatures. The heat sink effect of the wood studs within the wall on the temperature rise of the section of cable passing through them is demonstrated both with experiment and calculation.

17. KEY WORDS (six to twelve entries; alphabetical order; capitalize only the first letter of the tirst key word unless a proper uame; separated by semicolons)

Electric wiring; resistive heating; thermal insulation; thermal model; wiring system.

\begin{tabular}{|l|c|}
\hline $\begin{array}{l}\text { 19. SECURITY CLASS } \\
\text { (THIS REPORT) } \\
\text { UNCLASSIFIED }\end{array}$ & $\begin{array}{c}\text { 21. NO. OF } \\
\text { PRINTED PAGES }\end{array}$ \\
\hline $\begin{array}{l}\text { 20. SECURITY CLASS } \\
\text { (THIS PAGE) }\end{array}$ & 28 \\
UNCLASSIFIED & $\$ 6.00$ \\
\hline
\end{tabular}



